\title{
Article
}

\section{The Effect of Proprioceptive Training on Directional Dynamic Stabilisation}

\author{
Rhodes, David, Leather, M, Birdsall, D and Alexander, Jill \\ Available at http://clok.uclan.ac.uk/32879/ \\ Rhodes, David ORCID: 0000-0002-4224-1959, Leather, M, Birdsall, D and \\ Alexander, Jill ORCID: 0000-0002-6492-1621 (2020) The Effect of \\ Proprioceptive Training on Directional Dynamic Stabilisation. Journal of Sports \\ Rehabilitation . pp. 1-7. ISSN 1056-6716
}

It is advisable to refer to the publisher's version if you intend to cite from the work. http://dx.doi.org/10.1123/jsr.2019-0346

For more information about UCLan's research in this area go to

http://www.uclan.ac.uk/researchgroups/ and search for < name of research Group>.

For information about Research generally at UCLan please go to http://www.uclan.ac.uk/research/

All outputs in CLoK are protected by Intellectual Property Rights law, including Copyright law. Copyright, IPR and Moral Rights for the works on this site are retained by the individual authors and/or other copyright owners. Terms and conditions for use of this material are defined in the policies page.

\section{CLoK}

Central Lancashire online Knowledge www.clok.uclan.ac.uk

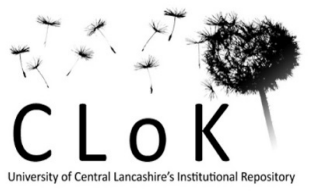


1 The Effect of Proprioceptive Training on Directional Dynamic Stabilisation

2

3 Authors:

4 Rhodes, $\mathrm{D}^{\mathrm{a}}$., Leather $\mathrm{M}^{\mathrm{a}}$., Birdsall, $\mathrm{D}^{\mathrm{a}}$., Alexander, $\mathrm{J}^{\mathrm{a}}$.

6 a Rehabilitation Sciences, University of Central Lancashire, Preston, Lancashire, PR1 2HE,

7 United Kingdom.

8

9 Email: Drhodes2@uclan.ac.uk

10

11

12

13

14

15

16

17

18

19

20

21

22

23

24

25

26

27

28

29

30

31

32

33

34

35

36

\section{Key words: proprioception, training, dynamic stability, soccer, injury risk}

.

7

8

9

0

1

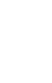


Objectives: Significant loss of playing time and the impact of treatment costs due to lower limb injury in football demonstrates a need for improved protocols for injury risk reduction. The aim of the present study is to assess the effect of a proprioceptive training programme on the lower limb dynamic stability of elite footballers.

Methods: Sixteen elite premier league footballers were randomly allocated by matched pair design to an 8-week proprioception training group (group $\mathrm{A}, \mathrm{n}=8$ ) or non-training group (group $\mathrm{B}, \mathrm{n}=8$ ), to determine the effect of this training over a 16-week period. Group A completed 8 weeks of bilateral proprioceptive training, 5 times per week for 10 minutes. Biodex Dynamic Stability (BSS) measures of Overall Stability Index (OSI), Anterior-Posterior (A-P), Medial-Lateral Stability (M-L) at levels 8-6-4-1 were taken for both groups at baseline, 4, 8 and 16 weeks. Main effects of time, level of stability and direction of stability were determined, with comparisons of effect made between the two groups.

Results: The training group displayed significant differences for multi directional stability at week 8 ( $\mathrm{P} \leq 0.05)$. A-P stability within the training group displayed significant differences between baseline measures and 16 weeks $(\mathrm{P}>0.05)$, with significant increases in scores displayed for M-L and A-P stability between weeks 8 and $16(\mathrm{P} \leq 0.05)$, representing a detraining effect. No significant differences were detected at any time point for the nontraining group $(\mathrm{P}>0.05)$.

Conclusions: Proprioceptive training over 8 weeks has a positive effect on all directions of stability. Greater declines in A-P stability were evident at 16 weeks when compared to M-L and OSI. Consideration must be given to the increased stability scores presented pre testing for A-P when compared to M-L. Findings of this work present implications for training design. 


\section{Introduction}

The sport of football, being the most popular in the world continues to increase in participation, subsequently so does the risk and frequency of sustaining injury [1, 2]. The resultant, costs of treatment and loss of playing time still demonstrates a need for improved injury risk reduction protocols, with Ekstrand et al, 2019 [3] reporting average time losses of 4 weeks due to injury in professional football. Evolving epidemiological information provides an understanding of injury incidence, recently highlighted injury incidence rates for matches and training was 11.5 per 1000 match-hours monitored over 6-season of profession level football [4]. Football places both physical and physiological demands on players, which becomes more evident at higher levels of competition. Considerable injury-risk associated with significant economic burden and subsequent impact to the success of competitive play in football at professional levels is reported [5].

One of the most serious injuries in modern professional football is rupture of the Anterior Cruciate Ligament (ACL) with an occurrence rate of 0.066 per $1000 \mathrm{hrs}$ of exposure and a median timescale of 7.4 months to return to match play following reconstruction [6]. The study also found match ACL injury rate was 20 times higher than the training injury rate $0.340 \mathrm{vs}$ 0.017 per 1000 hrs. Ankle injury accounts for 10-18\% of all injuries in high-level football [79). More than $75 \%$ of the ankle sprains in these studies affect the lateral ligaments as a result of inversion of the ankle joint. Following musculoskeletal injury, empirical investigations indicate that athletes are prone to enter a vicious succession known as the continuum of disability [10]. Reductions in sensorimotor control postulated to emerge from known damage structurally to mechanoreceptors of the affected ligament and associated tissues [4]. Examples such as chronic ankle instability following repeated ankle sprains in football demonstrates evidence to support this continuum [11]. Previous injury and inadequate rehabilitation are important intrinsic factors for future injury [12], due to mechanical and functional instability predisposing athletes to repetitive injury.

Dynamic stabilisation is heavily reliant on an efficient neuromuscular pathway [13] with evidence highlighting the positive effect of 3-5 stability-training sessions per week $[14,15]$. Within each of the aforementioned studies the balance training was completed on a variety of surfaces including foam pads and wooden discs, both acknowledging the effectiveness of differentiated surfaces to challenge the neuromuscular response of the athlete. Although, 
previous findings are conclusive with regards frequency of training and effect, limitations are evident. These include the influence of training on the level of stability tested, influence of training on directional stability and the longer-term effects of a proprioceptive training period. Ligamentous ankle injury leads to proprioceptive deficits, and reductions in joint position sense (JPS) relating to the athlete's perception of the position of a joint with their vision occluded and minimal feedback given [16]. Trauma to mechanoreceptors within tissue can result in partial de-afferentiation leading to proprioceptive deficits [17]. Therefore, it is imperative for optimum rehabilitation programmes designed specifically to include proprioceptive components to promote healing and minimise risk of re-injury [18]. Mechanical loading of a joint stimulates reflex muscular stabilisation through spinal reflexes; this can be achieved through various proprioceptive training methods reported in current literature [19]. Increasing the knowledge of the duration required for an optimal training effect on directional stability, could potentially optimise rehabilitation/ injury prevention strategies. Measurement of stability in previous research has been ascertained via multiple outcome measures, which can include; goniometers, Y-Balance, Star Excursion Balance Test, isokinetic dynamometers, postural sway via force plate, surface electromyography, stability systems [20, 21, 22]. The Biodex stability system (BSS) commonly utilised in sport assesses the ability of the athlete to maintain balance and postural control in multi directional planes [23], with conclusions supporting reliability of this tool to quantify dynamic stability [24].

Proprioceptive deficits resulting from lower limb injury in football requires proprioceptive training over a period of weeks, through balance and coordination exercises, in order to restore stabilometry $[14,15]$. Due to the multi directional nature of football, it is important to consider the mechanism of injury associated with specific lower limb injury when considering a player's rehabilitation or training plan. Therefore, the aim of the present study is to assess the effect of an 8-week proprioceptive training program on multi directional stability, observing effect on multi directional dynamic stability over a 16 -week period.

\section{Methods}

\section{Participants}

From an available squad of twenty-three, sixteen elite premier league footballers were available to volunteer for the study and took part in a sixteen-week proprioception intervention 
programme (age $17.60 \pm 0.85$ years, height $176.83 \pm 9.8 \mathrm{~cm}$ and body mass $69.7 \pm 12.9 \mathrm{~kg}$ ). A minimum sample size was based on sixteen players who met the inclusion / exclusion criteria of; no history of previous lower limb injury in the last 6 months and highlighted by the clubs medical team as having no mechanical or functional instability in the knee or ankle at time of testing. Players included were also free from systemic or vestibular disorders known to impair cutaneous sensation of balance [15]. In total, seven players were excluded from partaking in the study due to: injury ( $n=3$ ), playing position (goalkeepers' $n=2$ ), unavailable due to being on loan to another club $(\mathrm{n}=2)$. All participants taking part in the study provided written and informed consent, with study approval provided by the Ethics Committee of the host university. The authors hypothesised that a positive training effect in the group exposed to proprioceptive training would occur for all directions of stability.

Experimental Design

Participants were randomly allocated to one of two groups (Randomisation.com), being intervention (Group A, $\mathrm{n}=8$ ) and non-training group (Group B, $\mathrm{n}=8$ ). Group A undertook an eight-week ankle proprioceptive training programme (Table 1) in addition to their normal football training and competitive fixture demands. Group B underwent their normal football training and competitive fixture demands, with no additional proprioceptive training. Dynamic stability measures were completed for both groups at weeks 4, 8 and 16. All testing and training interventions were completed at the host club, an elite premier league football club, in an ambient temperature-controlled environment.

Examination of the effects of an 8-week ankle proprioceptive training programme in professional footballers measured through the BSS (Biodex Medical Systems, Shirley, NY), determined a score output at baseline, then again at 4, 8 and 16 weeks. All measures were taken between 13:00 and 17:00 hrs at all-time points to account for the effects of circadian rhythm $[25,26]$ and in accordance with regular training and competition times. The BSS (Biodex Medical Systems, Shirley, NY) is an unstable platform that can tilt up to $20^{\circ}$ in any direction, with the stability of the platform determined by the level by which it is set ranging from 1 (most unstable) to 12 (most stable) [27]. Each limb tested individually at levels 8-6-41 of stability on the BSS (Level 8 = more stable / Level $1=$ less stable). All testing on the BSS was completed barefoot due to the effect footwear can have on kinematics of the foot and muscle activity in the lower limb [28]. 
173 Participants undertook a familiarisation test trial, performed on each limb at all levels prior to testing 7 days prior to testing beginning. The participants completed 3 trials of 20 seconds on stability level 1 , once completed measures were calculated based on the amount of tilt in degrees for OSI, A-P and M-L. A low index score indicated high stability and high score a low level of stability. Players were asked to repeat trials if it was judged they required further familiarisation with the testing equipment. The BSS was setup in accordance with previous literature [29].

The BSS platform was set at a maximum of 20 degrees surface tilt. Subjects instructed to stand on the platform tried to balance and hold the platform level for a period. The subjects' ability to control the angle of tilt quantified as variance from neutral position. Before testing on the BSS began the subjects were asked to remove all footwear and socks. They then stood on the platform in full extension with their dominant limb with their foot in the centre of the platform. The feedback screen was set at eye level and the participants were asked to observe the screen, this was set as such to avoid any unwanted head movement and avoid vestibular distraction. Subjects were then asked to adjust their standing foot to a comfortable position, while the marker on the feedback screen maintained a central position. Once this was completed and the participant reported to be in a comfortable position the platform was locked into a stable position and the players' foot position was recorded. Once recorded the foot position remained consistent through each trial throughout the testing period. In between each trial players were told to weight-bear through the contralateral limb to minimise the effect of fatigue when testing. In cases where subjects lost their balance, they were told to use the contralateral limb to stabilise themselves by placing it at the back corner of the BSS and were only encouraged to use the handrails if they completely lost balance. The same assessor followed the same exact testing protocol throughout, applying individual configurations for each participant. The assessor was blinded as to which group each participant was allocated to for testing to avoid testing bias and improve validity of the results. Figure 1 provides a representation of the testing set-up. Testing protocol consisted of a single-leg hold for 20-seconds at levels 8-6-4-1. Each subject performed the assessment on alternate limbs for each level with a 1-minute period of rest in between each level.

$$
\text { *** Insert Figure } 1 \text { here }{ }^{* * *}
$$


Prior to completion of any proprioceptive training participants completed a warm up on a cycle ergometer. Participants were asked to maintain a speed of 70-watts and completed at this moderate intensity for a period of ten minutes. Post completion of the warm up on the cycle ergometer participants were supervised through a series of dynamic stretches, which included the hamstrings, quadriceps, adductors, abductors and gastrocnemius. The stretches were completed as four sets of three with each set lasting 30 -second period and this was consistent for all participants [30]. The training programme supervised by the same Sports Scientist at the club, was carried out in a performance gymnasium environment. The training programme performed by Group A, was applied five times per week at 9:45am, prior to football training schedules, accounting for the effects of circadian rhythm [25. 26]. All participants in the training programme group were barefoot and performed exercises for 10-minutes on five pieces of equipment (x1 Trampet, x1 Wobble Board, x1 Sissal Pad, x1 Foam Pad and x1 Gymnastic Beam). Within those 10-minutes, on each piece of equipment subjects spent 1-minute balancing on the right limb, followed by 1-minute balanced on the left limb, then instructed to repeat. Participants were timed by the Sports Scientist using a stopwatch for standardisation of time spent on each piece of equipment. Each piece of equipment and testing was performed within the performance gymnasium on a hard floor surface. For each exercise on each piece of equipment, the subject placed their arms across their chest with eyes open. All exercises, varying surfaces/equipment, timings and frequency of training were modelled on previous literature displaying positive effects on overall stability index scores [14, 15].

\section{Statistical Analysis}

A univariate repeated measures general linear model quantified main effects for training, time, level and direction of stability. Interaction effects were also quantified, and significant main effects of training were explored using post hoc pairwise comparisons with a Bonferonni correction factor. The assumptions associated with the statistical model were assessed to ensure model adequacy. To assess residual normality for each dependant variable, q-q plots were generated using stacked standardised residuals. Scatterplots of the stacked unstandardized and standardised residuals were also utilised to assess the error of variance associated with the residuals. Mauchly's test of sphericity was also completed for all dependent variables, with a

240 Greenhouse Geisser correction applied if the test was significant. Partial eta squared $\left(\eta^{2}\right)$ values 
were calculated to estimate effect sizes for all significant main effects and interactions. As recommended by Cohen (1988) [31], partial eta squared was classified as small (0.01-0.059), moderate (0.06-0.137), and large ( $>0.138)$. All statistical analysis was completed using PASW Statistics Editor 22.0 for windows (SPSS Inc, Chicago, USA). Statistical significance was set at $P \leq 0.05$, and all data are presented as mean \pm standard deviation.

\section{Results}

Table 1 summarises the training effect on stability scores of OSI, A-P and M-L, illustrating percentage differences at each time point when compared to pre training levels.

$$
\text { ***Insert table } 1 \text { here } * * *
$$

Analysis of the overall data set (inclusive of both the the training and non-training group) identified a significant effect for time $\left(F=13.22, P<0.001, \eta^{2}=0.056\right)$, level of stability test $\left(F=37.24, P<0.001, \eta^{2}=0.143\right)$, direction of stability $\left(F=132.6, P<0.001, \eta^{2}=0.283\right)$ and group $\left(F=78.3, P<0.001, \eta^{2}=0.104\right)$. Significant interactions were displayed for time $x$ level $\left(F=4.84, P<0.001, \eta^{2}=0.061\right)$, time $x$ direction interaction $\left(F=9.03, P<0.001, \eta^{2}\right.$ $=0.08)$ and time $x$ group $\left(F=2.8, P<0.05, \eta^{2}=0.01\right)$.

On separation of the data sets in to the training and non-training group significant effects for time $\left(F=10.66, P<0.001, \eta^{2}=0.087 ; F=5.58, P=0.001, \eta^{2}=0.047\right)$, level of stability test $\left(F=12.86, P<0.001, \eta^{2}=0.103 ; F=25.78, P \leq 0.001, \eta^{2}=0.187\right)$, direction of stability $\left(F=53.77, P<0.001, \eta^{2}=0.242 ; F=80.13, P \leq 0.001, \eta^{2}=0.323\right)$ and group $(F=78.29$, $\left.P<0.001, \eta^{2}=0.242 ; F=80.13, P \leq 0.001, \eta^{2}=0.323\right)$ were found.

No significant differences were identified between any time points within the non-training group, when compared to pre testing levels $(P>0.05)$. A time $x$ level $(F=3.35, P=0.001$, $\left.\eta^{2}=0.082\right)$ and time $x$ direction interaction $\left(F=7.34, P \leq 0.001, \eta^{2}=0.12\right)$ was identified. Conversely, the training groups week 8 values were significantly lower when compared to baseline measures post completion of the training protocol $(P<0.008)$, with no significance differences displayed at week 4 and $16(P>0.05)$. A time $x$ level $\left(F=2.06, P \leq 0.05, \eta^{2}=\right.$ $0.052)$ and time $x$ direction interaction $\left(F=2.96, P=0.008, \eta^{2}=0.50\right)$ was also found. 
276 With the data set collapsed for the training group to consider each direction of stability, all 277 directions displayed a significant effect of time (OSI: $F=5.46 ; P=0.002, \eta^{2}=0.128$; A-P: $F$ $278=3.89 ; P=0.01, \eta^{2}=0.10 ; \mathrm{M}-\mathrm{L}: F=7.96 ; P \leq 0.001, \eta^{2}=0.18$ ). Significant reductions in 279 A-P stability scores were displayed at 4 and 8-weeks post training when compared to pre 280 training levels $(P \leq 0.05)$, with $\mathrm{M}-\mathrm{L}$ and OSI stability displaying positive significant training effects at week 8. Significant increases in stability scores were displayed for A-P stability at 16 weeks $(P \leq 0.05)$, representing a detraining effect post training. Contrastingly, OSI and ML identified significant decreases compared to pre training levels $(P \leq 0.05)$. It was also noted

284

285 that a significant training effect was observed between week 4 and 16 and for A-P stability $(P$ $\leq 0.05)$. Significant differences were also displayed between week 8 and 16 in both A-P and M-L stability displaying a de-training effect within the training group $(P \leq 0.05)$ (Mean Scores Range: Week 8: A-P: 1.11 - 1.49; M-L: 0.94 - 1.32; Week 16: A-P 1.13 - 1.71; M-L: 0.99 1.54). A significant main effect was also displayed for level of stability within the training group (OSI: $F=3.92, P=0.01, \eta^{2}=0.10$; A-P: $F=4.06, P=0.001, \eta^{2}=0.128$; M-L: $F=$ 5.49, $P=0.001, \eta^{2}=0.13$ ), with significant differences only displayed between level 1 and 8 $(P=0.007)$.

Analysis of the collapsed data considering each direction of stability for the non-training group identified no significant effect of time in any direction (OSI: $\mathrm{F}=0.52, P=0.67, \eta^{2}=0.1$; AP: $F=10.12, P=0.14, \eta^{2}=0.05$; M-L: $\left.F=9.91, P \geq 0.05, \eta^{2}=0.42\right)$. A significant main effect was displayed for level of stability (OSI: $P<0.001, \eta^{2}=0.16$; A-P: $P \leq 0.001, \eta^{2}=$ 0.21; M-L: $P \leq 0.001, \eta^{2}=0.21$ ), with significant differences displayed between level 1 and $6(\mathrm{P} \leq 0.001)$ and level 1 and $8(P \leq 0.001)$, in all directions.

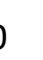

1

2

3

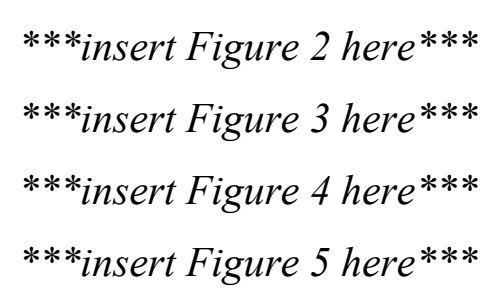

(1)

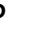

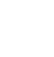


The aim of the present study was to investigate the effects of an eight-week proprioception training protocol over a 16-week period on multi directional dynamic stability. Previous research has highlighted the positive training response elicited post a period of proprioceptive training consisting of 3 - 5 training sessions per week. The training periods within literature have varied between 4 - 8 weeks, and the current work observes a longer-term effect, post completion of the 8-week training period. Present literature is also limited in relation to directional stability, although methods have been utilised that would quantify directional stability, they have not been analysed in isolation $[14,15]$.

Main findings within this body of work indicate significant proprioceptive training effects for all directions of stability at week 8 at all levels, with A-P and M-L displaying significant differences in stability scores at week 8 and 16 . Indicating, that cessation of training post 8 weeks had a decreased impact on stability scores within these directions. It was also identified that significant improvements of A-P stability were identified at 4 weeks post the initiation of training. No significant differences were detected at any time point for the non-training group. Thus, highlighting the importance of continued training to improve multi directional dynamic stabilisation.

Observation of the training groups directional stability mean scores and percentage changes across each time point for all levels shows a reduction within the period of training, indicating an improvement up to 8 weeks. Post 8 weeks, a detraining effect can be seen where mean scores move back towards baseline levels, with the exception of levels 6 and 8 . Further analysis of the mean scores and percentage changes indicate that improvements in stability scores are evident at levels 6 and 8 in both the training and non-training group. In addition, the training group highlight improvements at levels 1 and 4 within the training period, with reductions in stability performance at week 16. Conversely, the non-training group display reductions in directional stability performance throughout the 16-week period. Thus, supporting current research that more unstable platforms within BSS testing are more appropriate for elite level athletes [24].

Analysis of the mean scores for OSI, A-P and M-L stability display higher stability scores for OSI across all levels compared to A-P and M-L, which is unsurprising considering that OSI is 
a combination of A-P and M-L stability. These findings highlight the limitations that exist within present literature which analyse training effects on dynamic stability $[14,15]$. Further, observation of mean stability scores indicates higher values of stability for A-P from baseline to week 16 when compared to M-L, suggesting that the A-P stability is weaker in this population. Potentially, suggesting increased potential for injury risk within this plane when associating it with common mechanisms of sustaining ACL injury in footballers.

Previous research in the area has identified that integration in to the training schedule of $3-5$ proprioceptive sessions per week for $4-10$ minutes per session in elite footballers, has a positive impact on proprioceptive output [14]. The current study followed a training schedule of 5 sessions per week for 10 minutes per session collected at the same time each week. Previous literature has not accounted for circadian rhythm [25, 26]. Applying this in practice can be challenging due to coach demands, time restriction and fixture congested periods [32] and further work is required around maintenance of proprioceptive levels. This would add to the current body of work and allow practitioners to periodise training appropriately to accommodate these demands. It is important to note that literature has identified minimal time investment and the integration of such practices within warm ups have been shown to reduce injury risk [33]. Thus, identifying the importance of educating players and coaches for the need of such training, but also highlighting key windows for practitioners to integrate these methods with minimal disruption to the training schedule. Caution must be taken with the interpretation of the results of the current study due to small participant numbers; future work should consider a larger sample.

Common injuries sustained by footballers are often associated with the knee and ankle, with mechanisms of sustaining these injuries often not singularly associated with one plane of movement $[34,35]$. Examples of this exist when observing the ankle inversion sprain and ACL injuries, thus emphasising the importance of multi directional stability. Findings from the present study indicate a positive training effect over an 8-week training period for all directions of stability when compared to the non-training group. Time $x$ direction interactions were observed in both the training and non-training groups. Indicating a difference between directions of stability over time. Thus, highlighting that the changes in direction over time were different depending on the direction of stability observed. 
Interestingly collapsed data assessing individual directional differences indicated a training effect observed within all directions of stability at 8 weeks, with A-P stability displaying a significant positive training effect at week 4 when compared to baseline. Leaving the assumption that 4 weeks of proprioceptive training is adequate to improve A-P stability. In addition, it is important to note that A-P stability identifies a significant improvement in stability scores between training weeks 4 and 8 . A significant increase in A-P and M-L stability between weeks 8 and 16 when training stopped, was also identified. Thus, suggesting a decline in A-P and M-L stability when training was stopped. Observation of mean scores indicated this decline was highlighted in testing levels 1 and 4, where mean scores increased representing a decline in stability performance Mean Scores Range: Week 8: A-P: 1.11 - 1.49; M-L: 0.94 1.32; Week 16: A-P 1.13 - 1.71; M-L: 0.99 - 1.54. Reasons for this are unclear.

Performance of anterior stability would result in an increased anterior shearing force placed on the lower limb, stimulating a neuromuscular response to engage the hamstring muscles to provide stability to the joint $[36,37]$. Literature is contradictory as to the number of mechanoreceptors detected in the ACL compared with other stabilising structures in the knee $[38,39,40]$. It is important to note the higher mean scores displayed pre training in the training exposure group, when compared to M-L stability scores. Potentially, the reduced number of mechanoreceptors detected within the ACL could provide one possible explanation for this. Although not quantified in the current study, it is important to consider current findings and previous evidence highlighting that proprioceptive training improves the efficiency of the neuromuscular response, not the composition or number of mechanoreceptors [38]. Within the present study it is evident that 4 weeks of proprioceptive training improves A-P stability and these improvements can be attributed to increased neuromuscular efficiency within this plane, despite mechanoreceptor number. This could also potentially provide an explanation for the greater decline in mean scores post the cessation of training in A-P stability. Findings emphasise the importance of continued proprioceptive training to minimise injury risk in all directions of stability, but emphasise a greater effect on A-P stability. Further research should consider analysis of changes in the electromyography of the muscles in relation to directional stability, to determine efficiency in the muscular response to the unstable surface.

Utilisation of a variety of levels to assess elite footballer's stability on the BSS has been questioned, with level 1 being the most appropriate level of assessment for this population [24]. Interestingly a time $x$ level interaction was observed for the data within both the training and 
non-training groups. Suggesting that over time significant differences were found between the levels, potentially supporting earlier findings. When collapsing the data however, the present study highlights no significant differences between level 1 and 4 directional stability scores. Potentially advocating the use of level 4 directional stability assessment in elite footballers, particularly those that are recovering from injury. Note that caution should be taken in the interpretation of these findings due to the number of participants utilised and further research is required.

Recent studies have indicated the positive effects of proprioceptive training on dynamic stability $[14,15]$. Directional stability has been identified as a key aetiological factor associated with sustaining many non-contact lower limb musculoskeletal injuries [13]. Consideration of the mechanisms associated with common joint injuries sustained at the knee and ankle, indicate that injuries sustained at these joints can often be associated with multi planar movement patterns [33, 34]. The findings of the current research highlight varying training effects on directional stability (OSI, A-P and M-L), identifying differences within the training response of OSI, M-L and A-P stability. It is suggested from current findings that OSI, M-L and A-P stability all display improvements as a result of an 8-week training protocol completed for 10 minutes, five times a week. However, A-P stability shows greater declines if training is stopped and this potentially has implications for injury risk.

\section{Conclusions}

Proprioceptive training was shown to have a positive effect on dynamic stability scores in elite footballers, across all levels of stability tested on the BSS. Consideration should be given to the level of testing on the BSS, with no significant differences reported between levels 1 and 4 for stability scores achieved by elite footballers. When observing the long-term effect of an 8week training period on OSI, A-P and M-L stability it was evident that post 8 weeks of training stability performance had been improved, with A-P stability showing improvements post 4 weeks. Interestingly, observations of stability performance at 16 weeks, saw greater declines in A-P stability compared to OSI and M-L. Providing key considerations for practitioners when periodising proprioceptive training as part of their injury risk reduction strategies. Careful consideration must also be given to the implications of these findings and their association with the MOI of common lower limb injuries sustained in football. Injury risk reduction strategies or rehabilitation of the athlete post injury would need to carefully consider 
specific directional training and period completed within their training design, to minimise injury risk.

\section{References}

1. Rahnama N, Reilly T, Less A. Injury Risk Associated with Playing Actions During Competitive Soccer. Br J Sports Med. 2002;36:354-359.

2. Arnason A, Sigurdsson SB, Gudmundsson A, Holme I, Engebretsen L, Bahr R. Risk Factors for Injuries in football. Am J Sports Med. 2004;32:5-16.

3. Ekstrand J, Krutsch W, Spreco A, van Zoest W, Roberts C, Meyer T, Bengtsson H. Time before return to play for the most common injuries in professional football: a 16-year follow-up of the UEFA Elite Club Injury Study. Br J Sports Med. 2019;0:16.

4. Leventer L, Eek F, Hofstetter S, Lames M. Injury Patterns among Elite Football Players: A Media Based Analysis over 6 Seasons with Emphasis on Playing Position. Int J of Sports Med. 2016;37:898-908.

5. Ekstrand J. Keeping your Top Players on the Pitch: The Key to Football Medicine at a Professional Level. Br J Sports Med. 2013;47:723-724.

6. Walden M, Hagglund M, Magnusson H, Ekstrand J. ACL injuries in Men's Professional Football: A 15 year Prospective Study on Time Trends and Return to Play Rates Reveals only 65\% of Players Still Play at the Top level 3 years after ACL Rupture. Br J Sports Med. 2016;50:744-750.

7. Hawkins RD, Fuller CW. A Prospective Epidemiological Study of Injuries in Four English Professional Football Clubs. Br J Sports Med. 2001;33:196-203.

8. Woods C, Hawkins R, Maltby S, Hulse M, Thomas A, Hodson A. The Football Association Medical Research Programme: An Audit of Injuries in Professional Football - Analysis of Hamstring Injuries. Br J Sports Med. 2004;38:36-41.

9. Walden M, Hagglund M, Ekstrand J. Time-Trends and Circumstances Surrounding Ankle Injuries in Men's Professional Football: An 11 year Follow up of the UEFA Champions League Injury Study. Br J Sports Med. 2013;47:748-753.

10. Wikstrom EA, Hubbard-Turner T, McKeon PO. Understanding and Treating Lateral Ankle Sprains and their Consequences. Sports Med. 2013;43:385-393. 
11. Von Porat A, Roos EM, Roos H. High Prevalence of Osteoarthritis 14 years after an Anterior Cruciate Ligament Tear in Male Soccer Players: A Study of Radiographic and Patient Relevant Outcomes. Ann Rheum Dis. 2004;63:269-273.

12. Ekstrand J, Hagglund M, Walde M. Epidemiology of Muscle Injuries in Professional Football (Soccer). Am J Sports Med. 2011;39:1226-1232.

13. Croix MBA, Elnagar YO, Iga J, James D, Ayala F. Electromechanical Delay of the Hamstrings during Eccentric Muscle Actions in Males and Females: Implications for Non-Contact ACL Injuries. J Electro Kinesiol. 2015;25:901-906.

14. McHugh MP, Tyler TF, Mirabella MR. The Effectiveness of a Balance Training Intervention in Reducing the Incidence of Non-Contact Ankle Sprains in High School Football Players. Am J Sports Med. 2007;35:1289-1294.

15. Gioftsidou A, Malliou P, Pafis G, Beneka A, Tsapralis K, Sofokleous P, Kouli O, Roka S, Godolias G. Balance Training Programs for Soccer Injuries Prevention. $J$ Human Sport Ex. 2012;7:639-647.

16. Hertel J. Functional Instability Following Lateral Ankle Sprain. Sports Med. 2000;29:361-371.

17. Lephart SM, Kocher MS, Fu FH, Borsa PA, Harner CD. Proprioception Following Anterior Cruciate Ligament Reconstruction. J Sport Rehab. 1992;1:188-96.

18. Haidary M. Effects of Proprioception Exercises in the Rehabilitation Process of Football Players after Arthroscopic Surgery Anterior Cruciate Ligament (ACL). $J$ Sport Biomech. 2017;3:15-25.

19. Witchalls J, Turnbull M, Pacecca E. A Neuromuscular Training Programme for Reduction of Leg Injury Risk in Netball: Improving those at Greater Risk. $J$ Sci Med Sport. 2014;18:108-135.

20. Ribeiro F, Venancio J, Quintas P and Oliveira J. The Effect of Fatigue on Knee Position Sense is not dependent on the Muscle Group Fatigued. Muscle Nerve. 2010;44:217-220.

21. Thomas AC, McLean SG, Palmieri-Smith RM. Quadriceps and Hamstrings Fatigue Alters Hip and Knee Mechanics. J App Biomech. 2010;2:159-170.

22. LópezValenciano A, Ayala F, De Ste Croix M, Barbado D, VeraGarcia F. Different Neuromuscular Parameters Influence Dynamic Balance in Male and Female Football Players. Knee Surg Sports Traumatol Athrosc. 2018;27:1-9. 
23. Hosseini S, Hejazi K, Abbasian S, Khazaie M, Azimkhani A. Effect of Fatigue Protocol on Dynamic Balance in Soccer Players with Functional Ankle Instability. Austrail J Basic App Sci. 2013;7:468-472.

24. Pickerill ML, Harter RA. Validity and Reliability of Limits-of-Stability Testing. A Comparison of 2 Postural stability Devices. J Athl Train. 2011;46:600-606.

25. Blonc S, Perrot S, Racinais S, Aussepe S, Hue O. Effects of 5 Weeks of Training at the Same Time of Day on the Diurnal Variations of maximal Muscle Power Performance. J Strength Con Res. 2010;24:23-29.

26. Malhorata D, Narula R, Zutshi K. Effect of Time of Day and Concentric or Eccentric Strength Training on Muscle Strength. Indian J Physio Occ Ther. 2014;8:134-138.

27. Schmitz K, Arnold B. Intertester and Intratester Reliability of the Biodex Stability System. J Sport Rehab. 1998;7:95-101.

28. Franklin S, Grey MJ, Heneghan N, Bowen L, Li FX. Barefoot vs Common Footwear: A Systematic Review of Kinematic, Kinetic and Muscle Activity Differences during Walking. Gait \& Posture. 2015;42:230-239.

29. Arifin N, Osman NAA, Abas WAB. Intrarater Test-Retest Reliability of Static and Dynamic Stability Indexes Measurement Using the Biodex Stability System During Unilateral Stance. J App Biomech. 2014;30:300-304.

30. Herda TJ, Cramer JT, Ryan ED, McHugh MP, Stout JR. Acute Effects of Static Versus Dynamic Stretching on Isometric Peak Torque, Electromyography, and Mechanomyography of the Biceps Femoris Muscle. $J$ Strength Cond Res. 2008;22:809-817.

31. Cohen J. Statistical Power Analysis for the Behavioural Sciences. $2^{\text {nd }}$ Edition. Hillsdale, NJ: Lawrence Earlbaum Associates;1988.

32. McCall A, Dupont G, Ekstrand J. Injury Prevention Strategies, Coach Compliance and Player Adherence of 33 of the UEFA Elite Club Injury Study Teams: A Survey of Teams Head Medical Officers. Br J Sports Med. 2015;50:725-730.

33. Whitaker JL, Emery CA. Impact of the FIFA $11+$ on the Structure of Select Muscles in Adolescent Female Soccer Players. Phys Ther Sport. 2015;16:228-235.

34. Boden BP, Dean GS, Feagin JA Jr, Garrett WE Jr. Mechanisms of Anterior Cruciate Ligament Injury. Orthopedics. 2000;23:573-578.

35. Fauno P, Wulff Jakobsen B. Mechanism of ACL Injuries in Soccer. Int J Sports Med. 2006; 27:75-79. 
557

558

559

560

561

562

563

564

565

566

567

568

569

570

571

572

573

36. Letafatkar K, Alizadeh MH, Kordi MR. The Effect of Exhausting Exercise Induced Muscular Fatigue on Functional Stability. J Social Sci. 2009;4:416-422.

37. Cordeiro N, Cortes N, Fernandes O, Diniz A, Pezarat-Correia P. Dynamic Knee Stability and Ballistic Knee Movement after ACL Reconstruction: An Application on Instep Soccer Kick. Knee Surg Sports Traumatol Athrosc. 2014;23:1100-1106.

38. Hogervorst T, Brand RA. Current Concepts Review: Mechanoreceptors in Joint Function. The J Bone Joint Surg. 1998;89:1365-1378.

39. Lee B, Min K, Choi HS, Kwon SW, Chun D, Yun ES, Lee DW, Jin SY, Yoo JH. Immunohistochemical Study of Mechanoreceptors in the Tibial Remnant of Ruptured Anterior Cruciate Ligament in Human Knees. Knee Surg Sports Traumatol Arthrosc. 2009;17:1095-1101.

40. Dhillon MS, Bali K, Prabhaker S. Proprioception in anterior cruciate ligament deficient knees and its relevance in anterior cruciate ligament reconstruction. Indian J Orthop. 2011;45:294-300.

57

59

(n)

.

.


575 Table 1. Training and Non-Training Group Data with \% difference for OSI, A-P and M-L Stability, from Pre 576 to 4, 8 and 16-Week Time Points.

\begin{tabular}{|c|c|c|c|c|c|c|c|c|c|}
\hline & & & Traini & Group & & & Non Train & ng Group & \\
\hline Time & Direc & & & & & & Le & & \\
\hline Point & tion & Level 1 & Level 4 & Level 6 & Level 8 & Level 1 & Level 4 & Level 6 & Level 8 \\
\hline Pre & OSI & $\begin{array}{c}2.12 \pm 0.7 \\
5\end{array}$ & $\begin{array}{c}1.80 \pm 0.3 \\
5\end{array}$ & $\begin{array}{c}1.98 \pm 0.4 \\
5\end{array}$ & $\begin{array}{c}1.96 \pm 0.5 \\
9\end{array}$ & $2.20 \pm 0.60$ & $1.91 \pm 0.54$ & $2.00 \pm 0.52$ & $\begin{array}{c}2.24 \pm 0.4 \\
4\end{array}$ \\
\hline & A-P & $\begin{array}{c}1.69 \pm 0.6 \\
7\end{array}$ & $\begin{array}{c}1.44 \pm 0.2 \\
9\end{array}$ & $\begin{array}{c}1.56 \pm 0.4 \\
7\end{array}$ & $\begin{array}{c}1.64 \pm 0.5 \\
2\end{array}$ & $1.83 \pm 0.45$ & $1.53 \pm 0.34$ & $1.66 \pm 0.40$ & $\begin{array}{c}1.80 \pm 0.3 \\
6\end{array}$ \\
\hline & M-L & $\begin{array}{c}1.52 \pm 0.4 \\
1\end{array}$ & $\begin{array}{c}1.45 \pm 0.2 \\
7\end{array}$ & $\begin{array}{c}1.28 \pm 0.2 \\
8\end{array}$ & $\begin{array}{c}1.23 \pm 0.4 \\
0\end{array}$ & $1.31 \pm 0.36$ & $1.09 \pm 0.32$ & $1.29 \pm 0.35$ & $\begin{array}{c}1.48 \pm 0.3 \\
1\end{array}$ \\
\hline $\begin{array}{l}4 \\
\text { Week }\end{array}$ & OSI & $\begin{array}{c}1.92 \pm 0.4 \\
7(10 \%)\end{array}$ & $\begin{array}{c}1.79 \pm 0.4 \\
0(1 \%)\end{array}$ & $\begin{array}{c}1.80 \pm 0.4 \\
4(9 \%)\end{array}$ & $\begin{array}{c}1.71 \pm 0.2 \\
6(13 \%)\end{array}$ & $\begin{array}{c}2.29 \pm 0.37 \\
(+4 \%)\end{array}$ & $\begin{array}{c}2.13 \pm 0.43 \\
(+10 \%)\end{array}$ & $\begin{array}{c}1.95 \pm 0.41 \\
(2 \%)\end{array}$ & $\begin{array}{c}1.91 \pm 0.2 \\
7(15 \%)\end{array}$ \\
\hline & A-P & $\begin{array}{c}1.42 \pm 0.3 \\
4(16 \%)\end{array}$ & $\begin{array}{c}1.34 \pm 0.2 \\
7(7 \%)\end{array}$ & $\begin{array}{l}1.26 \pm 0.3 \\
0(19 \%)\end{array}$ & $\begin{array}{c}1.21 \pm 0.2 \\
7(26 \%)\end{array}$ & $\begin{array}{c}1.82 \pm 0.32 \\
(1 \%)\end{array}$ & $\begin{array}{c}1.62 \pm 0.27 \\
(+6 \%)\end{array}$ & $\begin{array}{c}1.42 \pm 0.24 \\
(14 \%)\end{array}$ & $\begin{array}{l}1.31 \pm 0.2 \\
5(27 \%)\end{array}$ \\
\hline & M-L & $\begin{array}{c}1.44 \pm 0.3 \\
7(5 \%)\end{array}$ & $\begin{array}{c}1.29 \pm 0.2 \\
7(11 \%)\end{array}$ & $\begin{array}{l}1.44 \pm 0.3 \\
4(11 \%)\end{array}$ & $\begin{array}{c}1.47 \pm 0.3 \\
2(16 \%)\end{array}$ & $\begin{array}{c}2.06 \pm 0.36 \\
(+28 \%)\end{array}$ & $\begin{array}{c}1.89 \pm 0.36 \\
(+32 \%)\end{array}$ & $\begin{array}{c}1.59 \pm 0.18 \\
(+19 \%)\end{array}$ & $\begin{array}{l}1.61 \pm 0.2 \\
2(28 \%)\end{array}$ \\
\hline $\begin{array}{l}8 \\
\text { Week }\end{array}$ & OSI & $\begin{array}{c}1.81 \pm 0.4 \\
8(15 \%)\end{array}$ & $\begin{array}{l}1.61 \pm 0.3 \\
2(11 \%)\end{array}$ & $\begin{array}{c}1.52 \pm 0.2 \\
5(22 \%)\end{array}$ & $\begin{array}{l}1.34 \pm 0.1 \\
8(32 \%)\end{array}$ & $\begin{array}{c}2.36 \pm 0.60 \\
(+7 \%)\end{array}$ & $\begin{array}{c}2.04 \pm 0.42 \\
(+6 \%)\end{array}$ & $\begin{array}{c}1.77 \pm 0.42 \\
(11 \%)\end{array}$ & $\begin{array}{c}1.72 \pm 0.3 \\
1(23 \%)\end{array}$ \\
\hline & A-P & $\begin{array}{c}1.49 \pm 0.4 \\
1(12 \%)\end{array}$ & $\begin{array}{c}1.41 \pm 0.2 \\
7(2 \%)\end{array}$ & $\begin{array}{c}1.29 \pm 0.2 \\
1(17 \%)\end{array}$ & $\begin{array}{l}1.11 \pm 0.1 \\
6(32 \%)\end{array}$ & $\begin{array}{c}2.03 \pm 0.46 \\
(+10 \%)\end{array}$ & $\begin{array}{c}1.83 \pm 0.39 \\
(+16 \%)\end{array}$ & $\begin{array}{c}1.52 \pm 0.39 \\
(8 \%)\end{array}$ & $\begin{array}{c}1.47 \pm 0.3 \\
1(18 \%)\end{array}$ \\
\hline & M-L & $\begin{array}{c}1.32 \pm 0.3 \\
5(13 \%)\end{array}$ & $\begin{array}{l}1.09 \pm 0.3 \\
2(15 \%)\end{array}$ & $\begin{array}{l}1.03 \pm 0.1 \\
9(20 \%)\end{array}$ & $\begin{array}{c}0.94 \pm 0.1 \\
2(24 \%)\end{array}$ & $\begin{array}{c}1.49 \pm 0.45 \\
(+12 \%)\end{array}$ & $\begin{array}{c}1.29 \pm 0.33 \\
(+16 \%)\end{array}$ & $\begin{array}{c}1.03 \pm 0.19 \\
(20 \%)\end{array}$ & $\begin{array}{c}0.94 \pm 0.1 \\
2(34 \%)\end{array}$ \\
\hline $\begin{array}{l}16 \\
\text { Week } \\
\text { s }\end{array}$ & OSI & $\begin{array}{c}1.95 \pm 0.3 \\
1(8 \%)\end{array}$ & $\begin{array}{c}1.76 \pm 0.2 \\
7(2 \%)\end{array}$ & $\begin{array}{l}1.51 \pm 0.2 \\
0(24 \%)\end{array}$ & $\begin{array}{c}1.36 \pm 0.1 \\
6(31 \%)\end{array}$ & $\begin{array}{c}2.46 \pm 0.45 \\
(+11 \%)\end{array}$ & $\begin{array}{c}2.16 \pm 0.40 \\
(+12 \%)\end{array}$ & $\begin{array}{c}1.80 \pm 0.27 \\
(10 \%)\end{array}$ & $\begin{array}{c}1.70 \pm 0.2 \\
0(24 \%)\end{array}$ \\
\hline & A-P & $\begin{array}{l}1.71 \pm 0.2 \\
7(+1 \%)\end{array}$ & $\begin{array}{l}1.53 \pm 0.2 \\
3(+6 \%)\end{array}$ & $\begin{array}{l}1.31 \pm 0.1 \\
9(16 \%)\end{array}$ & $\begin{array}{l}1.13 \pm 0.1 \\
7(31 \%)\end{array}$ & $\begin{array}{c}2.11 \pm 0.35 \\
(+13 \%)\end{array}$ & $\begin{array}{c}1.82 \pm 0.30 \\
(+16 \%)\end{array}$ & $\begin{array}{c}1.53 \pm 0.21 \\
(8 \%)\end{array}$ & $\begin{array}{l}1.45 \pm 0.1 \\
7(19 \%)\end{array}$ \\
\hline & M-L & $\begin{array}{c}1.54 \pm 0.2 \\
5(1 \%)\end{array}$ & $\begin{array}{c}1.39 \pm 0.2 \\
1(4 \%)\end{array}$ & $\begin{array}{l}1.14 \pm 0.1 \\
8(11 \%)\end{array}$ & $\begin{array}{c}0.99 \pm 0.1 \\
0(20 \%)\end{array}$ & $\begin{array}{c}1.89 \pm 0.31 \\
(+21 \%)\end{array}$ & $\begin{array}{c}1.56 \pm 0.19 \\
(+17 \%)\end{array}$ & $\begin{array}{c}1.37 \pm 0.22 \\
(+6 \%)\end{array}$ & $\begin{array}{l}1.22 \pm 0.1 \\
9(18 \%)\end{array}$ \\
\hline
\end{tabular}

578

579

580 Figure 1. Experimental Set-Up for Biodex Stabilometry Testing. 
582

583

584 Figure 2: Training v's Non Training Group Stability Scores (Level 1 BSS).
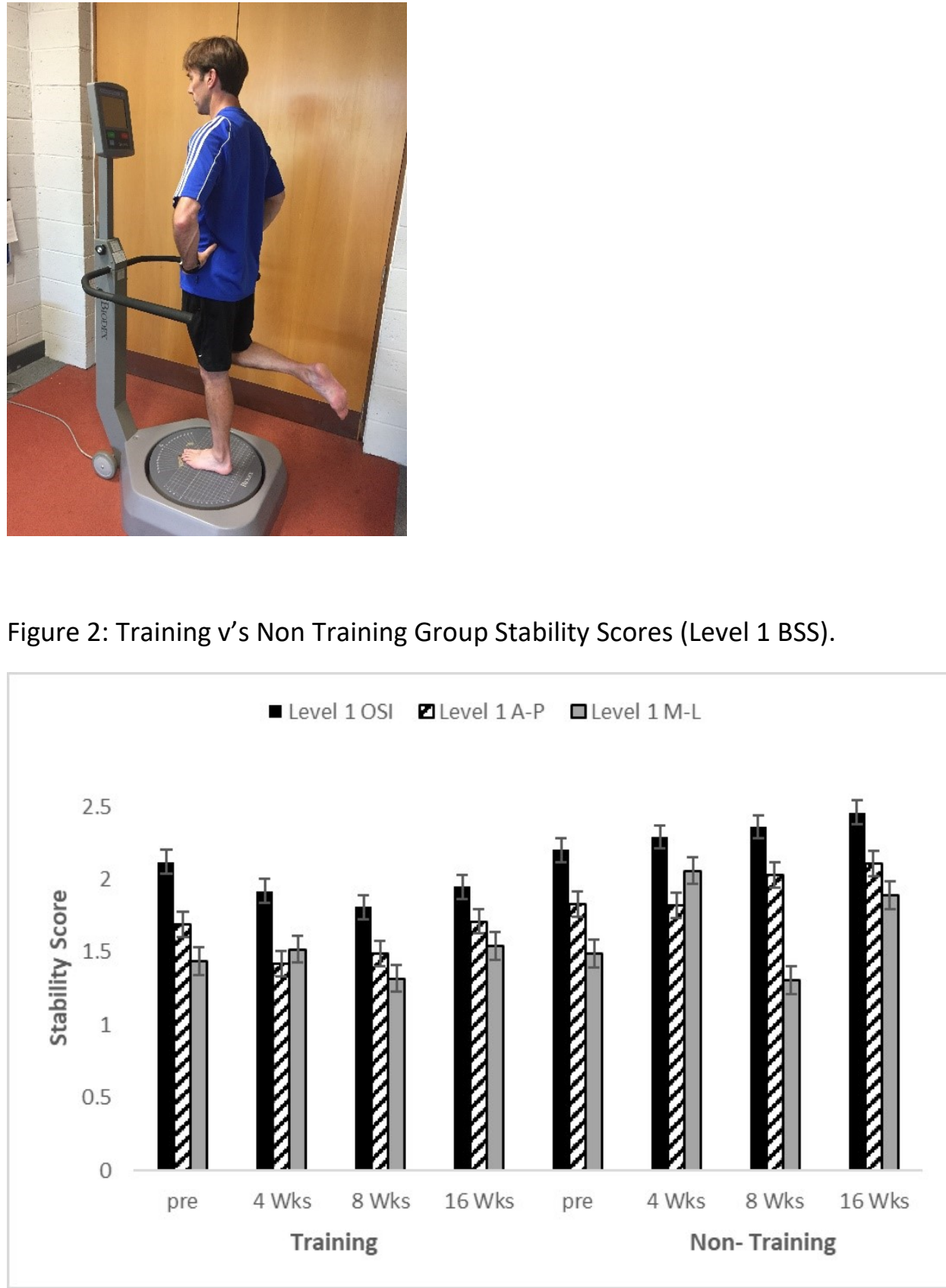

585

586

587

588

589

590

591

592

593

594 
600

601

602

603

604

605 Figure 3: Training v's Non Training Group Stability Scores (Level 4 BSS).
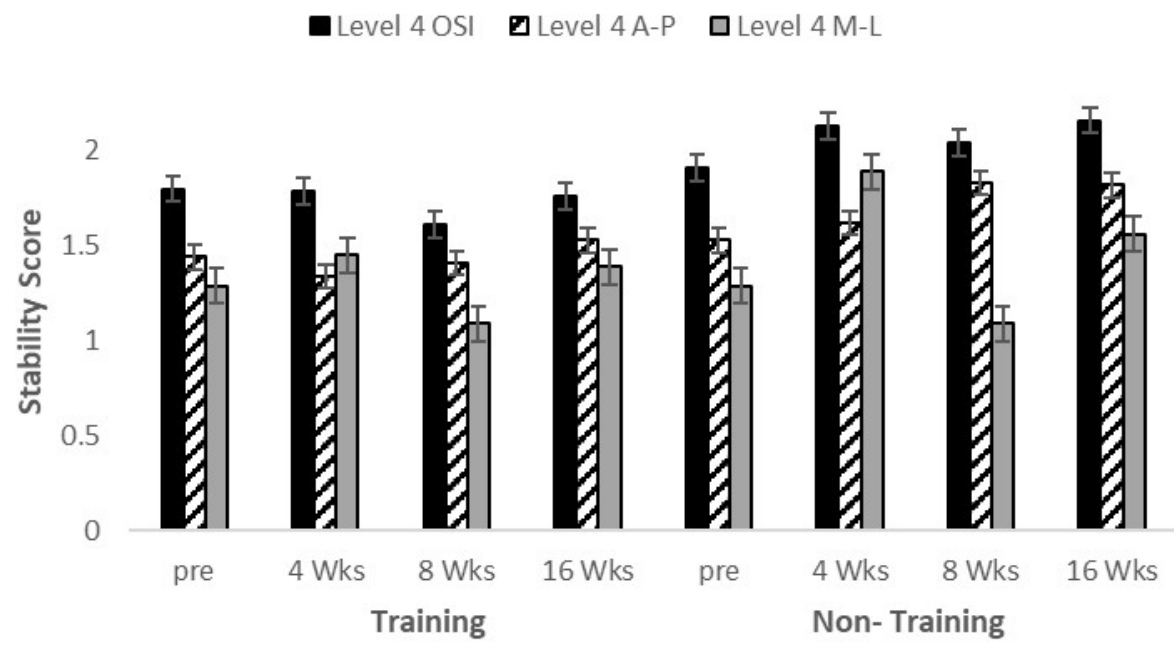

606

607

608

609

610

611

612

613

614

615

616 
617

618

619

620

621

622

623

624

625

626

627 Figure 4: Training v's Non Training Group Stability Scores (Level 6 BSS).

- Level 6 OSI $\boldsymbol{\square}$ Level 6A-P $\quad$ Level 6 M-L

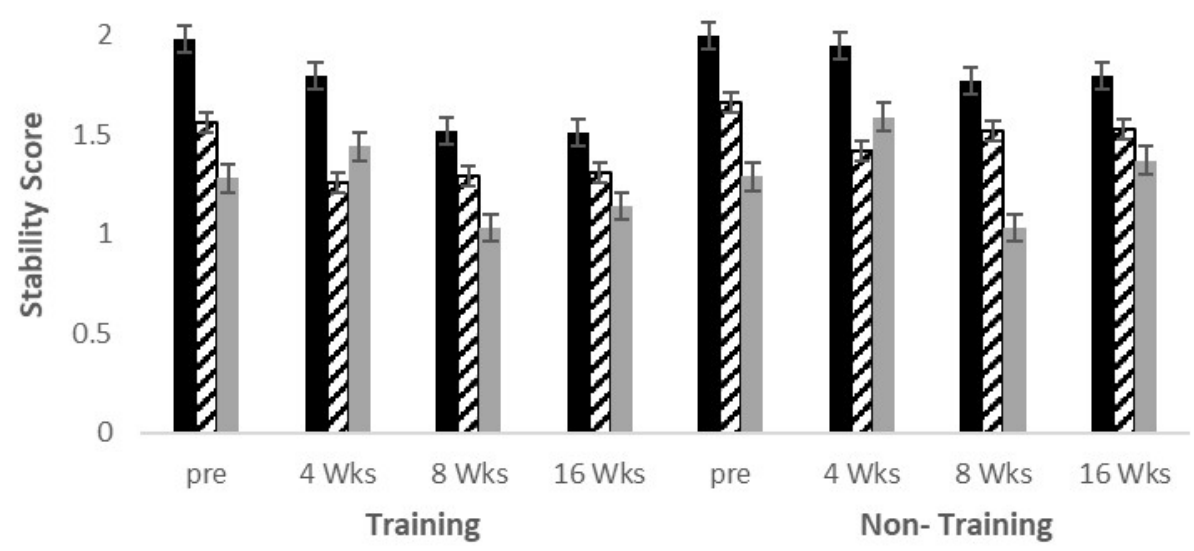

628

629

630

631

632

633

634

635

636

637

638 
639

640

641

642

643

644

645

646

647

648

649 Figure 5: Training v's Non Training Group Stability Scores (Level 8 BSS).

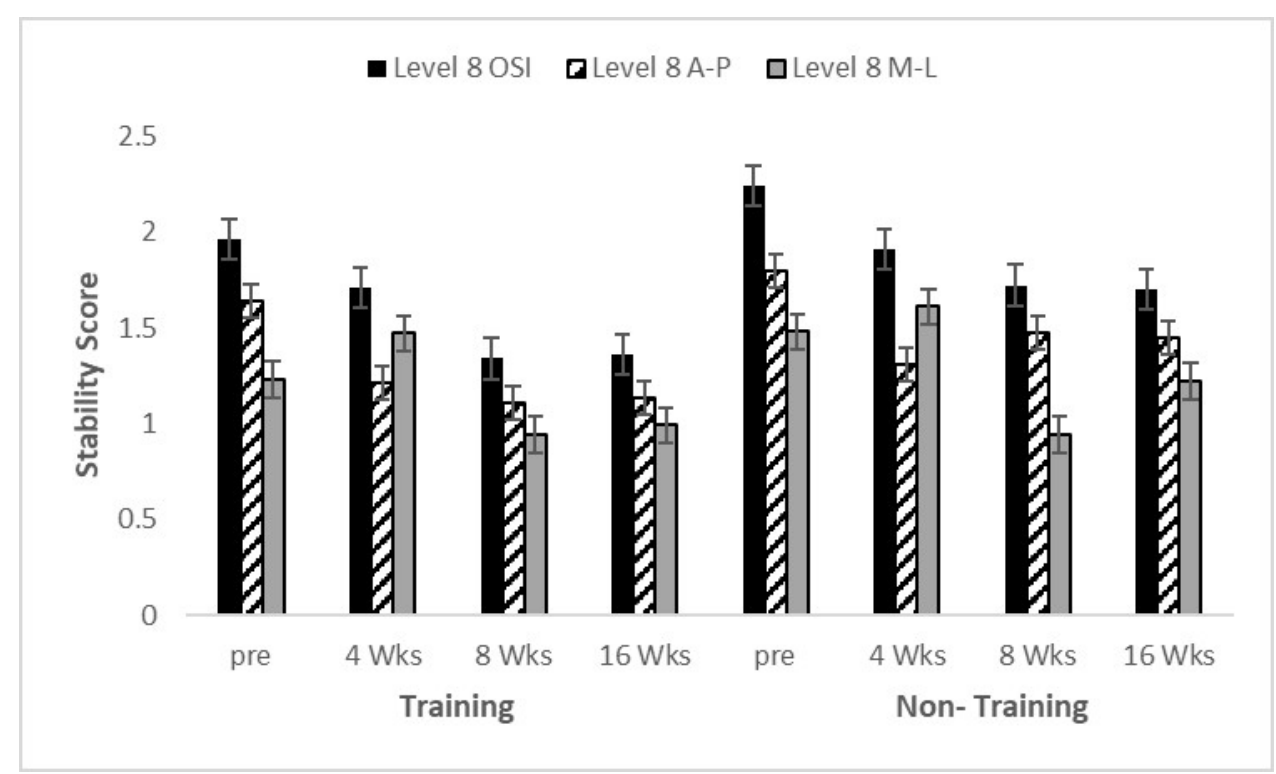

651 